\title{
Effect of Plasminogen Activator Inhibitor-1 and Tissue Plasminogen Activator Polymorphisms on Susceptibility to Type 2 Diabetes in Malaysian Subjects
}

\author{
Zaid Al-Hamodi, ${ }^{1}$ Riyadh Saif-Ali, ${ }^{1,2}$ Ikram S. Ismail, ${ }^{3}$ \\ Khaled A. Ahmed, ${ }^{4}$ and Sekaran Muniandy ${ }^{1}$ \\ ${ }^{1}$ Department of Molecular Medicine, Faculty of Medicine, University of Malaya, 50603 Kuala Lumpur, Malaysia \\ ${ }^{2}$ Department of Biochemistry, Faculty of Medicine, Sana'a, Yemen \\ ${ }^{3}$ Department of Medicine, University Malaya Medical Centre, University of Malaya, 50603 Kuala Lumpur, Malaysia \\ ${ }^{4}$ Faculty of Dentistry, Ibb University, Ibb, Yemen
}

Correspondence should be addressed to Zaid Al-Hamodi, zalhamodi@yahoo.com and Sekaran Muniandy, sekaran@um.edu.my

Received 16 October 2011; Revised 5 February 2012; Accepted 15 February 2012

Academic Editor: Leonid Medved

Copyright (C) 2012 Zaid Al-Hamodi et al. This is an open access article distributed under the Creative Commons Attribution License, which permits unrestricted use, distribution, and reproduction in any medium, provided the original work is properly cited.

Elevated activity of plasminogen activator inhibitor-1 (PAI-1) and decreased tissue plasminogen activator (tPA) activity are considered to be important risk factors for type 2 diabetes mellitus (T2DM) and metabolic syndrome (MetS). The aim of this study was to investigate the association of the PAI-1 4G/5G and tPA Alu-repeat I/D polymorphisms with T2DM in Malaysian subjects. Serum insulin, coronary risk panel, plasma glucose, and PAI-1 4G/5G and tPA Alu-repeat I/D polymorphisms were studied in 303 T2DM subjects (227 with MetS and 76 without MetS) and 131 normal subjects without diabetes and MetS. Statistical analysis showed that the dominant and additive models of PAI-14G/5G polymorphism showed a weak association with T2DM without MetS $(\mathrm{OR}=2.35, P=0.045 ; \mathrm{OR}=1.67, P=0.058)$. On the other hand, the recessive model of the tPA Alu-repeat I/D polymorphism showed an association with T2DM with MetS $(\mathrm{OR}=3.32, P=0.013)$ whereas the dominant and additive models of the tPA Alu-repeat I/D polymorphism were not associated with T2DM either with or without MetS.

\section{Background}

Diabetes mellitus is the most common endocrine disorder that affects 246 million people worldwide. The International Diabetes Federation (IDF) predicts that the number of people with diabetes mellitus will increase up to 380 million within twenty years [1]. Diabetes, mostly type 2 diabetes mellitus (T2DM), now affects $5.9 \%$ of the world's adult population with almost $80 \%$ of patients from developing countries [2]. More than 1.3 million of Malaysians have diabetes, and IDF predicts that this number would double by 2025 [1]. The number of individuals with the metabolic syndrome (MetS) has increased globally during the past two decades, and this increase is associated with the worldwide epidemic of obesity and diabetes [3].

Endothelial dysfunction is an emerging risk factor for type 2 diabetes. Obesity, together with the MetS, has a strong association with high PAI-1 levels [4-6]. Increased levels of proinsulin, C-peptide, and insulin have also been associated with high concentration of PAI-1 [7]. Recently, we reported that elevated plasma PAI-1, and reduced tPA activities were associated with an increased risk for T2DM among Malaysian subjects [6]. Several PAI-1 gene SNPs have been identified [8], among which the $4 \mathrm{G} / 5 \mathrm{G}$ polymorphism (rs1799889) located in the promoter region $-675 \mathrm{bp}$ upstream from the mRNA synthesis initiation point has been studied. Association of PAI-1 4G/5G polymorphism and variables related to the MetS were, however, unclear with carriers of the $4 \mathrm{G}$ allele being more prone to obesity and MetS in some studies [8-10] but not in others [11-13].

Alu-repeat I/D polymorphism was found in intron 8 of the tPA gene [14], and a number of populations have been found to be dimorphic for its presence or absence of repeats 
[15]. The association of PAI-1 with T2DM has not been reported in Malaysian subjects, and there is limited data on the association of Alu-repeat I/D polymorphism with T2DM worldwide. We studied the association of the PAI-1 4G/5G and tPA Alu-repeat I/D polymorphisms with T2DM with or without MetS as well as total T2DM in Malaysian subjects.

\section{Materials and Methods}

2.1. Subjects and Data Collection. For this study, a total of 434 Malaysian subjects aged 30-60 years were recruited. Diabetic subjects were randomly recruited from patients previously diagnosed with type 2 diabetes mellitus, who received treatment at the University Malaya Medical Centre (UMMC). After providing written informed consent, 303 T2DM subjects agreed to participate. Application of IDF criteria [16] resulted in 227 of T2DM with MetS and 76 without MetS.

In general, subjects (diabetic and normal) with acute or chronic infections, severe medical conditions (malignancy, renal failure, liver cirrhosis, connective tissue disease, and chronic congestive heart failure), and pregnant women were excluded from the study.

For the control group, the consent forms and brochures were distributed to the civil servant of the main office of Radio and Television Malaysia at Bukit Putra, Angkasapuri, Kuala Lumpur, Malaysia, through the Human Resource Department. In addition, consent forms and brochures were distributed to subjects who came to UMMC for medical checkup. After providing written informed consent, 190 normal subjects were randomly recruited for this study. Application of IDF criteria (for diagnose metabolic syndrome) [16] and WHO/IDF diagnosis of diabetes (FBG < $6.1 \mathrm{mmol} / \mathrm{L}$ ) [17] resulted in 131 subjects considered normal (without diabetes and metabolic syndrome).

The Medical Ethics Committee of UMMC approved the study. Fasting venous blood $(6 \mathrm{~mL})$ was collected from each subject after signed consent form. The collected blood was immediately taken into three labelled Vacutainer sodium fluoride (for glucose measurement), plain (for insulin and lipid profile), and EDTA tubes (for genetic analysis).

2.2. Biochemical Analysis. Serum TG, HDL-c, and plasma glucose were measured by an automated analyzer Dimension RxL Max Integrated Chemistry System. Insulin was measured by ADVIA Centaur assay XP Immunoassay System (Siemens Healthcare Diagnostics Inc. Deerfield, IL, USA). All these investigation were done at Division of Laboratory Medicine (LMC) of the UMMC, Kuala Lumpur, Malaysia. Insulin resistance (IR) was calculated using the homeostasis model assessment (HOMA2) calculator v2.2 which is available from the Oxford Centre for Diabetes, Endocrinology and Metabolism.

2.3. Genetic Analysis. Leukocyte genomic DNA was extracted from whole EDTA blood using a commercially Wizard Genomic DNA Purification Kit (Promega Corporation,
Madison, WI, USA) according to the manufacturer's instructions.

2.3.1. Genotyping of PAI-1 Polymorphisms. Allele-specific PCR was used to detect the genotypes of PAI-1 4G/5G. Two specific forward allele primers 5G, 5'GAGTCTGGACACGTGGGGG- $3^{\prime}$ at $3^{\prime}$ end is G, and $4 \mathrm{G}, 5^{\prime}$ GAGTCTGGACACGTGGGGA- $3^{\prime}$ at $3^{\prime}$ end the 5 th G was replaced by $\mathrm{A}$ as matching the subsequent sequence, were designed to detect this SNP. An internal control was included with each PCR reaction to ensure that there was PCR amplification. Therefore, common forward (upstream of allele-specific primers $5^{\prime}$-TGGTCCCGTTCAGCCACCA- $3^{\prime}$ ) and reverse primers (downstream of allele-specific primers $5^{\prime}$-ATGCAGCCAGCCACGTGAT- $3^{\prime}$ ) were used as PCR amplification controls with each PCR reaction. The reverse primer also is a reverse primer for the two allele-specific primers. Amplification reactions of PAI-1 were performed in two separated PCR reactions using $20 \mu \mathrm{L}$ volume of PCR contained $50 \mathrm{ng}$ of genomic DNA, 5 pmol of allelespecific primer $5 \mathrm{G}$ or $4 \mathrm{G}, 1.2 \mathrm{pmol}$ of forward primer, $5 \mathrm{pmol}$ of reverse primer, $1.5 \mathrm{mM} \mathrm{MgCl} 2,1 \mathrm{X}$ PCR buffer, 1X QSolution, $100 \mu \mathrm{M}$ dNTPs, and 0.5 unit of HotStarTaq Plus DNA Polymerase (Qiagen, Valencia, CA, USA). DNA was denaturated at $94^{\circ} \mathrm{C}$ for $5 \mathrm{~min}$, followed by 25 cycles of denaturation at $94^{\circ} \mathrm{C}$ for $1 \mathrm{~min}$, annealing at $63^{\circ} \mathrm{C}$ for $45 \mathrm{sec}$, and extension at $70^{\circ} \mathrm{C}$ for $75 \mathrm{sec}$, with a final extension step for $5 \mathrm{~min}$ at $72^{\circ} \mathrm{C}$. The PCR products were run by electrophoresis in a $7 \%$ polyacrylamide gel (PAG) and stained with ethidium bromide (EtBr). Band was visualized by the gel document system (Infinity 3026, Vilber Lourmat, Marne-la-Vallée, France).

2.3.2. Genotyping of tPA Polymorphism. An I/D polymorphism resulting from the presence or absence of Alurepeat in intron 8 of the tPA gene was assessed by PCR using the following primers [18]. sense primer: $5^{\prime}$ GTGAAAAGCAAGGTCTACCAG- $3^{\prime}$ and nonsense primer: $5^{\prime}$-GACACCGAGTTCATCTTGAC-3'. PCR reaction was performed in a $20 \mu \mathrm{L}$ volume with $10 \mathrm{pmol}$ of each primer, $200 \mu \mathrm{M}$ dNTP, $3 \mathrm{mM} \mathrm{MgCl} 2$, 1X PCR buffer, 1X Q-Solution, 1 unit HotStarTaq Plus DNA polymerase, and 50 ng genomic DNA. The samples were initially denaturated at $94^{\circ} \mathrm{C}$ for $5 \mathrm{~min}$ before being subjected to 30 cycles consisting of $1 \mathrm{~min}$ at $94^{\circ} \mathrm{C}$ (denaturation), $1 \mathrm{~min}$ at $60^{\circ} \mathrm{C}$ (annealing), and $75 \mathrm{sec}$ at $71^{\circ} \mathrm{C}$ (extension) in a thermal cycler followed by final extension at $72^{\circ} \mathrm{C}$ for $10 \mathrm{~min} .9 \mu \mathrm{L}$ of each product were electrophoresed on a $1 \%$ agarose gel, then stained by $\mathrm{EtBr}$ and visualized by the gel document system.

To validate the obtained results, samples of PCR products (64 of PAI- 1 and 46 of tPA) were sent to Bioneer Corporation (Daejeon, Republic of Korea) for sequencing. The sequencing results were in a good agreement with the PCR results. No errors in allele-specific PCR were detected.

2.4. Statistical Analysis. Calculations to determine whether observed genotype frequencies are consistent with the Hardy-Weinberg equilibrium (HW) that was done by the 
TABle 1: Demographic and biochemical parameters among normal and type 2 diabetes mellitus with or without metabolic syndrome subjects.

\begin{tabular}{|c|c|c|c|}
\hline \multirow{2}{*}{ Parameters } & \multirow{2}{*}{ Normal $(n=131)$} & \multicolumn{2}{|c|}{ Type 2 diabetes mellitus } \\
\hline & & Without MetS $(n=76)$ & With MetS $(n=227)$ \\
\hline \multicolumn{4}{|l|}{ Gender \% } \\
\hline Male/female & $34.6 / 65.4$ & $56.6 / 43.4$ & $42.7 / 57.3$ \\
\hline \multicolumn{4}{|l|}{ Races \% } \\
\hline Malay & 52.3 & 47.4 & 49.8 \\
\hline Chinese & 33.75 & 23.7 & 14.5 \\
\hline Indian & 13.75 & 28.9 & 35.7 \\
\hline Age (years) & $49.1 \pm 12.6$ & $50.7 \pm 9.0$ & $51.9 \pm 6.9$ \\
\hline Body mass index $\left(\mathrm{kg} / \mathrm{m}^{2}\right)$ & $23.0 \pm 3.8$ & $23.7 \pm 4.0$ & $30.0 \pm 4.2$ \\
\hline Waist circumference $(\mathrm{cm})$ & $79.9 \pm 11.0$ & $83.5 \pm 10.3$ & $98.9 \pm 8.5$ \\
\hline Diastolic blood pressure (mmHg) & $80.4 \pm 9.0$ & $79.8 \pm 9.4$ & $83.7 \pm 10.3$ \\
\hline Systolic blood pressure $(\mathrm{mmHg})$ & $132 \pm 18$ & $131 \pm 18$ & $138 \pm 18$ \\
\hline Triglyceride (mmol/L) & $1.15 \pm 0.56$ & $1.55 \pm 1.21$ & $1.98 \pm 1.25$ \\
\hline High-density lipoprotein $(\mathrm{mmol} / \mathrm{L})$ & $1.57 \pm 0.37$ & $1.24 \pm 0.31$ & $1.17 \pm 0.27$ \\
\hline Fasting blood glucose (mmol/L) & $5.04 \pm 0.51$ & $8.55 \pm 3.34$ & $8.20 \pm 3.15$ \\
\hline Insulin $(\mathrm{pmol} / \mathrm{L})$ & $53.3 \pm 35.5$ & $89.4 \pm 85.9$ & $150 \pm 104$ \\
\hline Insulin resistance (IR) & $1.00 \pm 0.66$ & $1.82 \pm 1.68$ & $3.00 \pm 1.98$ \\
\hline
\end{tabular}

The result presented as mean \pm standard deviation. MetS: metabolic syndrome. T: total.

TABle 2: Association of PAI-1 4G/5G polymorphisms with type 2 diabetes mellitus in Malaysian subjects.

\begin{tabular}{|c|c|c|c|c|}
\hline \multirow[b]{2}{*}{ PAI-1 4G/5G polymorphism } & \multirow[b]{2}{*}{ Control $(n=131)$} & \multicolumn{2}{|c|}{ Type 2 diabetes mellitus } & \multirow{2}{*}{$\begin{array}{l}\text { Total type } 2 \text { diabetes mellitus } \\
\qquad(n=303)\end{array}$} \\
\hline & & $\begin{array}{l}\text { Without MetS } \\
\quad(n=76)\end{array}$ & $\begin{array}{l}\text { With MetS } \\
(n=227)\end{array}$ & \\
\hline Risk allele frequency (4G) & 0.47 & 0.48 & 0.49 & 0.50 \\
\hline \multirow[t]{2}{*}{$(4 \mathrm{G} / 4 \mathrm{G}) /(4 \mathrm{G} / 5 \mathrm{G}) /(5 \mathrm{G} / 5 \mathrm{G})$ (frequency) } & $0.23 / 0.485 / 0.29$ & $0.25 / 0.54 / 0.21$ & $0.25 / 0.48 / 0.27$ & $0.25 / 0.50 / 0.25$ \\
\hline & Odds ratio & 1.8 & 0.66 & 0.78 \\
\hline \multirow[t]{3}{*}{ Recessive model } & $95 \% \mathrm{CI}$ & $(0.77-4.2)$ & $(0.31-1.4)$ & $0.37-1.66$ \\
\hline & $P$ value & 0.17 & 0.29 & 0.52 \\
\hline & Odds ratio & 2.35 & 1.61 & 1.5 \\
\hline \multirow[t]{3}{*}{ Dominant model } & $95 \% \mathrm{CI}$ & $1.0-5.43$ & $(0.9-2.91)$ & $0.72-1.7$ \\
\hline & $P$ value & 0.045 & 0.11 & 0.28 \\
\hline & Odds ratio & 1.67 & 1.1 & 1.1 \\
\hline \multirow[t]{2}{*}{ Additive model } & $95 \% \mathrm{CI}$ & $0.98-2.84$ & $0.75-1.6$ & $0.69-1.74$ \\
\hline & $P$ value & 0.058 & 0.63 & 0.69 \\
\hline
\end{tabular}

In the additive model, genotype of homozygote for the nonrisk allele 5G/5G (0/0), heterozygote 4G/5G (1/0), and homozygote for the risk allele 4G/4G (1/1) were coded as 0,1 , and 2 , respectively. The recessive model was defined as $4 \mathrm{G} / 4 \mathrm{G}$ versus $(4 \mathrm{G} / 5 \mathrm{G}+5 \mathrm{G} / 5 \mathrm{G})$, dominant model as $(4 \mathrm{G} / 4 \mathrm{G}+4 \mathrm{G} / 5 \mathrm{G})$ versus $5 \mathrm{G} / 5 \mathrm{G}$, and additive model as $4 \mathrm{G} / 4 \mathrm{G}$ versus $4 \mathrm{G} / 5 \mathrm{G}$ versus $5 \mathrm{G} / 5 \mathrm{G}$. The results presented odds ratio, $95 \%$ CI, and $P$ value adjusted for age, gender, race, family history of diabetes, and BMI as covariates which evaluated by hierarchical logistic regression. MetS: metabolic syndrome.

method of Court $(2005,2008)$. All other statistical analyses were done using Social Package of Statistical Science (SPSS) 11.5 (LEAD Technologies, Inc., USA). The missing data were listwise deleted-when any of the variables were missing, the entire observation was omitted from the analysis. The associations of the PAI-1 and tPA polymorphisms, recessive, dominant, and additive models with T2DM with or without MetS and total T2DM were evaluated by hierarchical logistic regression controlled for age, gender, race, history of diabetes, and BMI as covariates. The difference between means was considered significant when $P$ value $<0.05$.

\section{Results}

The demographic and biochemical parameters of the subjects are shown in Table 1.
The frequency of the minor allele (4G) of PAI-1 (0.47) was lower than that of the $5 \mathrm{G}$ allele $(0.53)$, whereas the frequency of tPA allele insertion (0.48) was lower than that of the allele deletion (0.52).

The results showed that the dominant and additive models of PAI-1 4G/5G polymorphism showed a weak association with T2DM without MetS $(\mathrm{OR}=2.35, P=0.045$; $\mathrm{OR}=1.67, P=0.058$ ), with no association for T2DM with MetS and total T2DM. Further, the recessive model showed no association of PAI-1 4G/5G genotype with T2DM with or without MetS (Table 2). On the other hand, the dominant and additive models of tPA Alu-repeat I/D were not a risk for T2DM with or without MetS and total T2DM. In contrast, the recessive model of tPA Alu repeat I/D genotype showed a risk factor for T2DM with MetS $(\mathrm{OR}=3.32$, 
TABLE 3: Association of tPA Alu repeat-I/D polymorphism with type 2 diabetes mellitus in Malaysian subjects.

\begin{tabular}{|c|c|c|c|c|}
\hline \multirow[b]{2}{*}{ tPA Alu repeat I/D polymorphism } & \multirow[b]{2}{*}{ Control $(n=131)$} & \multicolumn{2}{|c|}{ Type 2 diabetes mellitus } & \multirow[b]{2}{*}{$\begin{array}{l}\text { Total type } 2 \text { diabetes mellitus } \\
\qquad(n=303)\end{array}$} \\
\hline & & $\begin{array}{l}\text { Without MetS } \\
\quad(n=76)\end{array}$ & $\begin{array}{l}\text { With MetS } \\
(n=227)\end{array}$ & \\
\hline Risk allele frequency (Insertion) & 0.48 & 0.47 & 0.50 & 0.49 \\
\hline II/ID/DD (frequency) & $0.23 / 0.49 / 0.28$ & $0.28 / 0.50 / 0.22$ & $0.26 / 0.48 / 0.26$ & $0.25 / 0.49 / 0.26$ \\
\hline \multirow{3}{*}{ Recessive model } & Odds ratio & 1.88 & 3.32 & 1.34 \\
\hline & $95 \% \mathrm{CI}$ & $0.81-4.4$ & $1.28-8.57$ & $0.66-2.9$ \\
\hline & $P$ value & 0.14 & 0.013 & 0.39 \\
\hline \multirow{3}{*}{ Dominant model } & Odds ratio & 1.02 & 1.21 & 1.27 \\
\hline & $95 \%$ CI & $0.44-2.37$ & $0.51-2.9$ & $0.61-2.65$ \\
\hline & $P$ value & 0.96 & 0.66 & 0.52 \\
\hline \multirow{3}{*}{ Additive model } & Odds ratio & 1.28 & 1.48 & 1.24 \\
\hline & $95 \% \mathrm{CI}$ & $0.77-2.13$ & $0.87-2.51$ & $0.8-1.7$ \\
\hline & $P$ value & 0.34 & 0.15 & 0.34 \\
\hline
\end{tabular}

In the additive model, genotype of homozygote for the nonrisk allele $\mathrm{D} / \mathrm{D}(0 / 0)$, heterozygote $\mathrm{I} / \mathrm{D}(1 / 0)$, and homozygote for the risk allele I/I (1/1) was coded as 0,1 , and 2 , respectively. The recessive model was defined as $\mathrm{I} / \mathrm{I}$ versus $(\mathrm{I} / \mathrm{D}+\mathrm{D} / \mathrm{D})$, dominant model as $(\mathrm{I} / \mathrm{I}+\mathrm{I} / \mathrm{D})$ versus $\mathrm{D} / \mathrm{D}$ and additive model as $\mathrm{D} / \mathrm{D}$, versus I/D versus I/I. The results presented odds ratio, $95 \% \mathrm{CI}$ and $P$-value adjusted for age, gender, race, family history of diabetes and BMI as covariates which evaluated by hierarchical logistic regression. MetS: metabolic syndrome.

$P=0.013$ ) with no association for T2DM without MetS and total T2DM (Table 3). The association of PAI-1 4G/5G and tPA Alu repeat I/D polymorphisms with T2DM showed no significant differences when statistically analyzed adjusted for age, gender, race, and family history of diabetes as covariate without BMI (see Supplementary Tables S1 and S2 available online at doi:10.1155/2012/234937). Results were not altered by further adjustment for specific medications for hyperlipidaemia, hypertension, and hyperglycaemia. Univariate analyses showed that the PAI-1 4G/5G and tPA Alu-repeat I/D polymorphisms were not associated with the age of onset of diabetes (Supplementary Table S3).

\section{Discussion}

The association of the PAI-1 4G/5G and tPA Alu-repeat I/D polymorphisms with T2DM with or without MetS as well as with total T2DM was studied in Malaysian subjects. In this study, there were no differences in the frequencies of both polymorphisms PAI-1 4G/5G and tPA Alu-repeat I/D between T2DM and normal subjects. The analysis of genetic models of PAI-1 4G/5G polymorphism (dominant and additive) showed a weak association of polymorphism with T2DM in Malaysian subjects. This weak association may be due to small sample size, particularly in the control group, and nonmatched gender. On the other hand, the recessive model of PAI-1 4G/5G polymorphism showed no association with T2DM in Malaysian subjects.

Previous studies had shown significant association with T2DM among the Chinese [19], Tunisian [20], and Pima Indian subjects [21]. However, other studies on Caucasian [8, 22-24], Japanese [25], and Framingham subjects [26] have reported that PAI-1 4G/5G polymorphism is not associated with T2DM. This variability of the genetic association can be explained, in part, by differences in the characterization of diabetic patients. In our study, patients were characterized as
T2DM with or without MetS, whereas in the studies of Wong et al. (2000) [19] and Ezzidi et al. (2009) [20] subjects were grouped as T2DM with nephropathy while in the study of Nagi et al. (1997) [21] subjects had T2DM with retinopathy. In addition, ethnicity and environmental factors may alter the phenotypic expression of the genes. Furthermore, our previous study reported that the plasma PAI-1 activity was significantly higher in Malaysian diabetic subjects with metabolic syndrome than normal [6]. In addition, we demonstrated that the level of plasma PAI-1 was higher in Malaysian normal subjects with homozygous 4G/4G and heterozygous $4 \mathrm{G} / 5 \mathrm{G}$ compared to PAI- 1 homozygous $5 \mathrm{G} / 5 \mathrm{G}$ genotypes [27].

Genetic data in this study also showed that no differences existed in the allelic frequencies of the insertion and deletion alleles between T2DM with or without MetS as well as total T2DM and normal groups. On the other hand, the recessive model, of the tPA Alu-repeat I/D polymorphism showed a risk factor for T2DM. However, there is limited data on the association of tPA Alu-repeat I/D polymorphism with diseases, while there are no available data on its association with T2DM. Further, its association with other diseases such as myocardial infarction [28], multiple sclerosis [29] and periodontitis [30] has been described. The analysis of these results showed that there is no association between the genetic polymorphisms of PAI-1 4G/5G and tPA Alu-repeat $\mathrm{I} / \mathrm{D}$ and the age of onset of diabetes.

\section{Conclusion}

The dominant model of PAI-1 4G/5G polymorphism showed a weak association with T2DM without MetS. On the other hand, the recessive model of tPA Alu repeat I/D polymorphism showed a risk factor for T2DM with MetS in Malaysian subjects. 


\section{Acknowledgments}

The authors wish to thank the University of Malaya and the research supported by grants from the Fundamental Research Grant Scheme (FRGS/PS251/2010B).

\section{References}

[1] International Diabetes Federation Diabetes Atlas, http://www .eatlas.idf.org/prevalence/.

[2] S. M. Sadikot and C. E. Mogensen, "Risk of coronary artery disease associated with initial sulphonylurea treatment of patients with type 2 diabetes: a matched case-control study," Diabetes Research and Clinical Practice, vol. 82, no. 3, pp. 391395, 2008.

[3] P. Zimmet, K. G. M. M. Alberti, and J. Shaw, "Global and societal implications of the diabetes epidemic," Nature, vol. 414, no. 6865, pp. 782-787, 2001.

[4] M. C. Alessi and I. Juhan-Vague, "PAI-1 and the metabolic syndrome: links, causes, and consequences," Arteriosclerosis, Thrombosis, and Vascular Biology, vol. 26, no. 10, pp. 2200 2207, 2006.

[5] R. H. Eckel, S. M. Grundy, and P. Z. Zimmet, "The metabolic syndrome," The Lancet, vol. 365, no. 9468, pp. 1415-1428, 2005.

[6] Z. Al-Hamodi, I. S. Ismail, R. Saif-Ali, K. A. Ahmed, and S. Muniandy, "Association of plasminogen activator inhibitor1 and tissue plasminogen activator with type 2 diabetes and metabolic syndrome in Malaysian subjects," Cardiovascular Diabetology, vol. 10, article 6, 2011.

[7] Anna., Mechanisms and Effects of Low Plasminogen Activator Inhibitor Type 1 Activity, Karolinska Institutet, 2008.

[8] C. Lopes, C. Dina, E. Durand, and P. Froguel, "PAI-1 polymorphisms modulate phenotypes associated with the metabolic syndrome in obese and diabetic Caucasian population," Diabetologia, vol. 46, no. 9, pp. 1284-1290, 2003.

[9] I. Juhan-Vague, P. E. Morange, H. Aubert et al., "Plasma thrombin-activatable fibrinolysis inhibitor antigen concentration and genotype in relation to myocardial infarction in the North and South of Europe," Arteriosclerosis, Thrombosis, and Vascular Biology, vol. 22, no. 5, pp. 867-873, 2002.

[10] M. W. Mansfield, M. H. Stickland, and P. J. Grant, "Environmental and genetic factors in relation to elevated circulating levels of plasminogen activator inhibitor-1 in Caucasian patients with non-insulin-dependent diabetes mellitus," Thrombosis and Haemostasis, vol. 74, no. 3, pp. 842-847, 1995.

[11] M. Freeman and M. Mansfield, “To: J. Hoffstedt et al. (2002) The common $-6754 \mathrm{G} / 5 \mathrm{G}$ polymorphism in the plasminogen activator inhibitor-1 gene is strongly associated with obesity," Diabetologia, vol. 45, no. 11, pp. 1602-1604, 2002.

[12] J. Hoffstedt, I. L. Andersson, L. Persson, B. Isaksson, and P. Arner, "The common $-6754 \mathrm{G} / 5 \mathrm{G}$ polymorphism in the plasminogen activator inhibitor-1 gene is strongly associated with obesity," Diabetologia, vol. 45, no. 4, pp. 584-587, 2002.

[13] L. Viitanen, J. Pihlajamäki, P. Halonen et al., "Association of angiotensin converting enzyme and plasminogen activator inhibitor-1 promoter gene polymorphisms with features of the insulin resistance syndrome in patients with premature coronary heart disease," Atherosclerosis, vol. 157, no. 1, pp. 5764, 2001.

[14] S. A. Tishkoff, G. Ruano, J. R. Kidd, and K. K. Kidd, "Distribution and frequency of a polymorphic Alu insertion at the plasminogen activator locus in humans," Human Genetics, vol. 97, no. 6, pp. 759-764, 1996.

[15] G. E. Novick, C. C. Novick, J. Yunis et al., "Polymorphic Alu insertions and the Asian origin of native American populations," Human Biology, vol. 70, no. 1, pp. 23-39, 1998.

[16] K. G. M. M. Alberti, P. Zimmet, and J. Shaw, "The metabolic syndrome-a new worldwide definition," The Lancet, vol. 366, no. 9491, pp. 1059-1062, 2005.

[17] WHO, "Definition and diagnosis of diabetes mellitus and intermediate hyperglycemia: report of a WHO/IDF consultation," in Definition and Diagnosis of Diabetes Mellitus and Intermediate Hyperglycemia: Report of a WHO/IDF Consultation, 2006.

[18] B. Y. Kang and K. O. Lee, "Genetic polymorphisms of t-PA and PAI-1 genes in the Korean population," Korean Journal of Biological Sciences, vol. 7, pp. 249-253, 2003.

[19] T. Y. H. Wong, P. Poon, C. C. Szeto, J. C. N. Chan, and P. K. T. Li, "Association of plasminogen activator inhibitor-1 4G/4G genotype and type 2 diabetic nephropathy in Chinese patients," Kidney International, vol. 57, no. 2, pp. 632-638, 2000.

[20] I. Ezzidi, N. Mtiraoui, M. Chaieb, M. Kacem, T. Mahjoub, and W. Y. Almawi, "Diabetic retinopathy, PAI-1 4G/5G and -844G/A polymorphisms, and changes in circulating PAI1 levels in Tunisian type 2 diabetes patients," Diabetes and Metabolism, vol. 35, no. 3, pp. 214-219, 2009.

[21] D. K. Nagi, L. J. McCormack, V. Mohamed-Ali, J. S. Yudkin, W. C. Knowler, and P. J. Grant, "Diabetic retinopathy, promoter (4G/5G) polymorphism of PAI-1 gene, and PAI-1 activity in Pima Indians with type 2 diabetes," Diabetes Care, vol. 20, no. 8, pp. 1304-1309, 1997.

[22] M. Broch, C. Gutierrez, C. Aguilar, I. Simon, C. Richart, and J. Vendrell, "Genetic variation in promoter $(4 \mathrm{G} / 5 \mathrm{G})$ of plasminogen activator inhibitor 1 gene in type 2 diabetes. Absence of relationship with microangiopathy," Diabetes Care, vol. 21, no. 3, article 463, 1998.

[23] J. B. Meigs, C. J. O’Donnell, G. H. Tofler et al., "Hemostatic markers of endothelial dysfunction and risk of incident type 2 diabetes: the Framingham Offspring Study," Diabetes, vol. 55, no. 2, pp. 530-537, 2006.

[24] B. Zietz, C. Buechler, W. Drobnik, H. Herfarth, J. Schölmerich, and A. Schäffler, "Allelic frequency of the PAI-1 4G/5G promoter polymorphism in patients with type 2 diabetes mellitus and lack of association with PAI-1 plasma levels," Endocrine Research, vol. 30, no. 3, pp. 443-453, 2004.

[25] H. Kimura, F. Gejyo, Y. Suzuki, S. Suzuki, R. Miyazaki, and M. Arakawa, "Polymorphisms of angiotensin converting enzyme and plasminogen activator inhibitor-1 genes in diabetes and macroangiopathy," Kidney International, vol. 54, no. 5, pp. 1659-1669, 1998.

[26] J. B. Meigs, J. Dupuis, C. Liu et al., "PAI-1 gene 4G/5G polymorphism and risk of type 2 diabetes in a populationbased sample," Obesity, vol. 14, no. 5, pp. 753-758, 2006.

[27] Z. H. Al-Hamodi, R. Saif-Ali, I. S. Ismail, K. A. Ahmed, and S. Muniandy, "Plasminogen activator inhibitor-1 4G/5G polymorphism is associated with metabolic syndrome parameters in Malaysian Subjects," Journal of Clinical Biochemistry and Nutrition. In press.

[28] W. Ahmed, M. Malik, I. Saeed et al., "Role of tissue plasminogen activator and plasminogen activator inhibitor polymorphism in myocardial infarction," Molecular Biology Reports, vol. 38, no. 4, pp. 2541-2548, 2011. 
[29] L. Lovrecic, S. Ristic, N. Starcevic-Cizmarevic et al., "PAI and TPA gene polymorphisms in multiple sclerosis," Multiple Sclerosis, vol. 14, no. 2, pp. 243-247, 2008.

[30] A. Gurkan, G. Emingil, B. H. Saygan et al., "Tissue plasminogen activator and plasminogen activator inhibitor-1 gene polymorphisms in patients with chronic periodontitis," Journal of Periodontology, vol. 78, no. 7, pp. 1256-1263, 2007. 

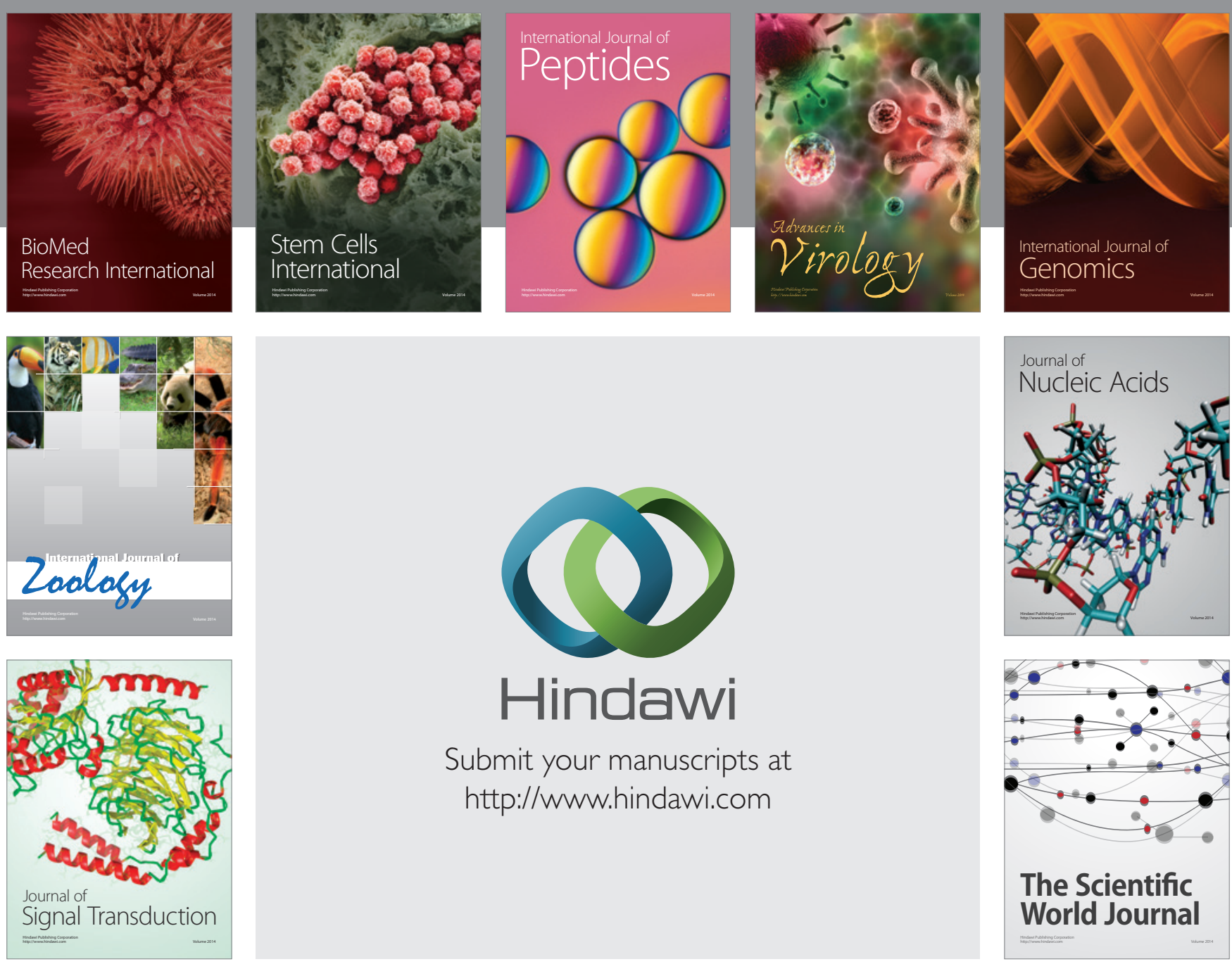

Submit your manuscripts at

http://www.hindawi.com
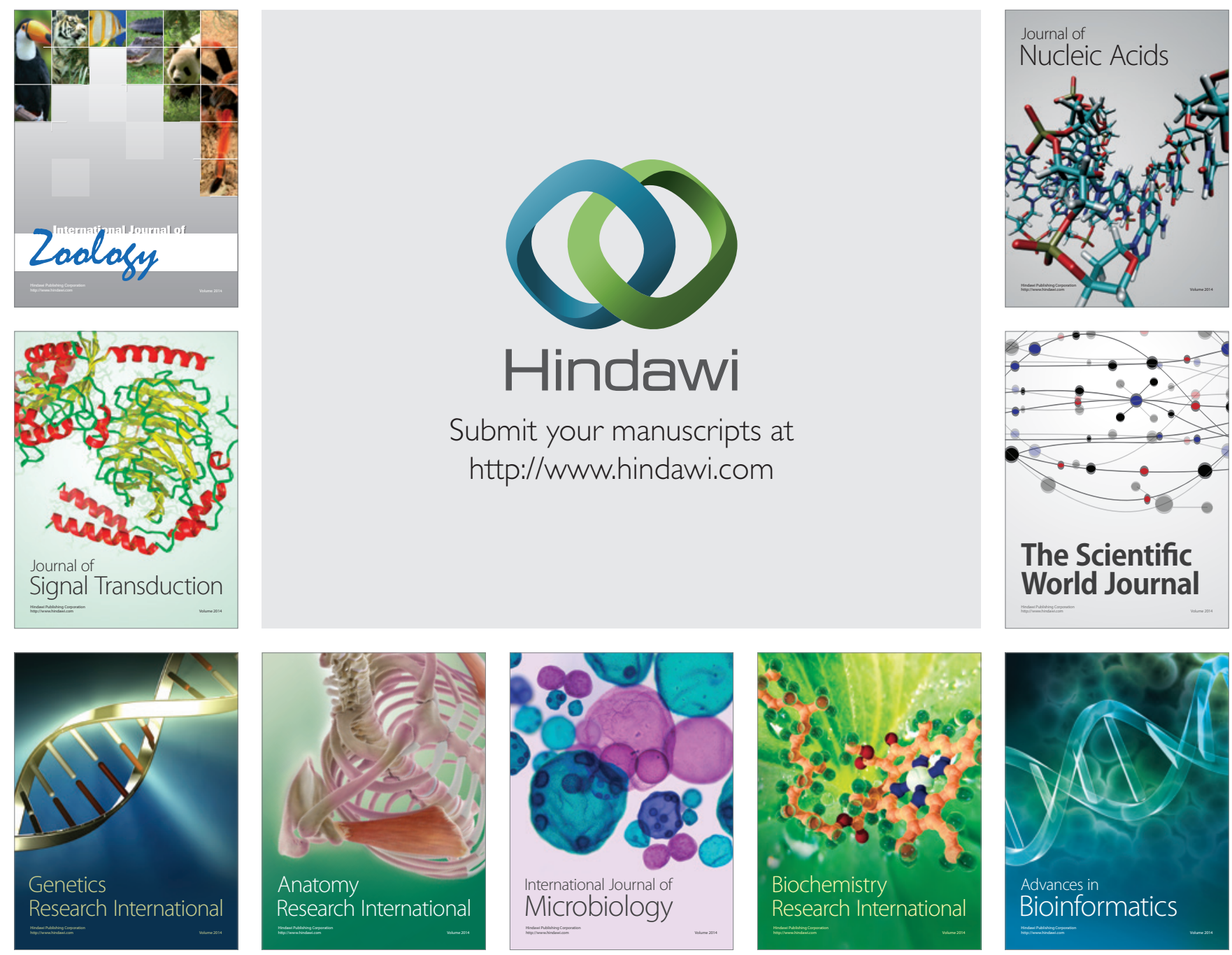

The Scientific World Journal
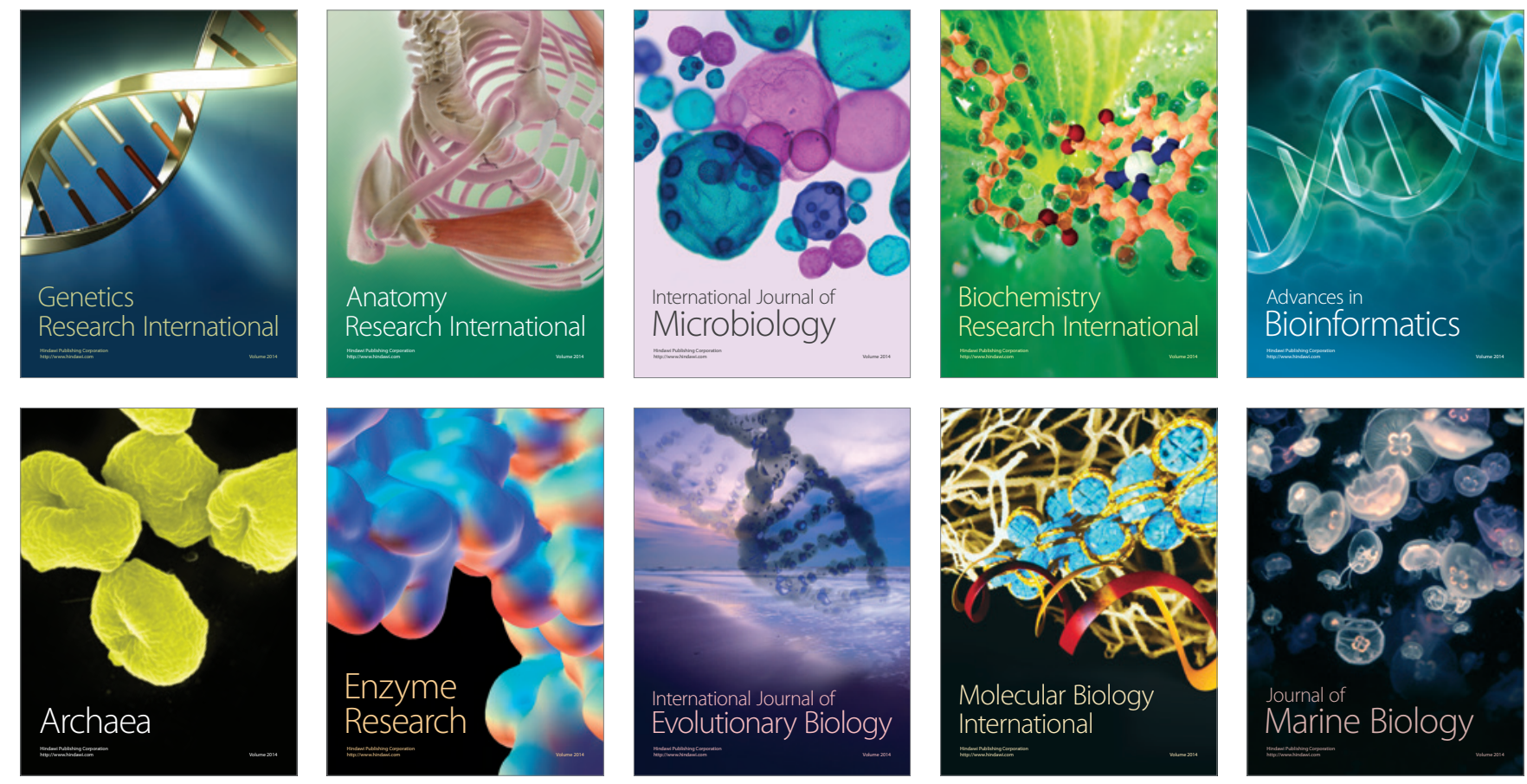